\title{
Análise da utilização de técnicas e ferramentas no programa Seis Sigma a partir de um levantamento tipo survey
}

\author{
Eduardo Guilherme Satolo UNIMEP \\ João Marcos Andrietta Elastotec S.A. \\ Paulo Augusto Cauchick Miguel UNINOVE \\ Felipe Araújo Calarge UNINOVE
}

\section{RESUMO}

O programa Seis Sigma é uma iniciativa adotada atualmente por muitas empresas e seu uso ocorre por meio de um processo altamente disciplinado e orientado, no qual são aplicadas diversas técnicas e ferramentas, que objetivam a geração de um ciclo de melhoria contínua. Diante desse fato e considerando a relevância do assunto, foi conduzido um levantamento tipo survey com o intuito de identificar e analisar as técnicas e ferramentas usadas nas etapas do método DMAIC e a sua comparação com a prescrição da literatura. Buscou-se levantar as técnicas e ferramentas mais e menos empregadas pelas empresas, permitindo-se confrontar estes resultados com outros levantamentos já realizados no exterior. Cabe destacar também que os resultados confirmaram o indicado pela literatura, os quais apontam que o programa Seis Sigma necessita apoiar-se em dados mensuráveis e confiáveis, evidenciando assim que o emprego das técnicas e ferramentas é indispensável junto ao método de melhoria DMAIC.

\section{Analysis on the usage of techniques and tools from the Six-Sigma program on a survey-type assessment}

\begin{abstract}
The Six-Sigma program is an approach currently adopted by many companies and its usage occurs through a highly disciplined and guided process, in which several techniques and tools are applied, trying to generate a continuous improvement cycle. Facing this fact and considering the relevance of the subject, a survey-based research was carried out. One of the objectives was to identify and analyse the techniques and tools used in the phases of the DMAIC and their comparison with the literature. The results consisted in assessing the techniques and tools most and least used by the companies, enabling to confront those with other previous research. It is also worthy highlighting that these results confirmed the indications of other publications, which state that the Six Sigma programme needs to be supported by measurable and trustworthy data. This makes evident that the usage of techniques and tools is indispensable for the DMAIC improvement method.
\end{abstract}

\section{KEY WORDS}

Six-Sigma program, Continuous improvement, DMAIC method, survey. 


\section{INTRODUÇÃO}

Atualmente, as empresas têm buscado vencer a concorrência melhorando a qualidade de seus produtos e o desempenho de seus processos. Assim, para manter a competitividade, as organizações aplicam diferentes práticas de gestão que, se utilizadas com critérios rigorosos e métodos disciplinados, possibilitam a superação dos concorrentes, em função da oferta de produtos e serviços de melhor qualidade (LINDERMAN et al., 2003).

O Six Sigma ou Seis Sigma - segundo a tradução utilizada no Brasil - é uma das práticas de gestão que as empresas vêm utilizando atualmente, com o propósito de preservarem a competitividade de seus negócios (ROTONDARO et al., 2002), pois a ênfase das organizações que aplicam o Seis Sigma é respaldar suas decisões em fatos concretos e dados mensuráveis, visando conseguir maior e melhor controle dos processos de produção ou serviços (PANDE et al., 2000).

O Seis Sigma é tratado por diferentes formas terminológicas, tanto pela lite-

ratura quanto pelas empresas que a adotam, sendo comum verificar termos que relacionam o Seis Sigma a "prática", "iniciativa", "metodologia", "técnica", "programa", "estratégia", dentre outros. Para fins deste artigo, será adotado o termo "Programa Seis Sigma", por entender esta prática de gestão como sendo um método estruturado, composto por etapas definidas, que visam atender metas preestabelecidas, resultando no termo "programa", considerando assim esta terminologia mais adequada para a aplicação dada pelas empresas.

Uma importante fase na condução do Programa Seis Sigma refere-se à aplicação do DMAIC, que é um método estruturado para solução de problemas, sendo esta sigla originada das letras iniciais de: Define (definir), Measure (medir), Analyse (analisar), Improve (melhorar) e Control (controlar). O DMAIC é um dos métodos mais citados, correspondendo a $75 \%$ de um total de 250 em um levantamento de artigos publicados no exterior (BRADY; ALLEN, 2006).

A partir do momento em que se percebe que as decisões devem basear-se em fatos concretos e dados mensuráveis, o emprego de técnicas e ferramentas torna-se imprescindível para a gestão. As técnicas e ferramentas foram estabelecidas por vários autores relacionados com a área de gestão da qualidade, sendo que algumas destas permanecem inalteradas desde a sua criação, ao passo que outras evoluíram e algumas, ainda, foram recentemente desenvolvidas (VIEIRA FILHO, 2003). Assim, o termo "técnicas e ferramentas" refere-se, neste artigo, às ferramentas típicas da área da qualidade e da área estatística (por exemplo, diagrama de Pareto, desdobramento da função qualidade - QFD, planejamento de experimentos, etc.) e áreas correlatas da engenharia de produção (como por exemplo; PERT/CPM, Poka-Yoke, etc.), algumas delas mais simples outras mais estruturadas.

O Programa Seis Sigma, que surgiu em 1987 na Motorola após a realização de uma série de estudos sobre a variação dos processos de produção com ênfase no conceito de melhoria contínua (HENDERSON; EVANS, 2000); visa, por meio da aplicação sistêmica e disciplinada de técnicas e ferramentas (ANTONY et al., 2007), melhorar a lucratividade de empresas de qualquer setor de atividade, aumentar a participação de mercado, reduzir custos e otimizar as operações, aprimorando a qualidade e promovendo a eliminação de defeitos, erros e falhas (FOLARON, 2003).

\section{A ênfase das organizações que aplicam 0 em fatos concretos e dados mensuráveis.}

Considerando a relevância do tema e diante da motivação e importância de obter uma maior quantidade de dados sobre a aplicação do Programa Seis Sigma no país, foi conduzido um levantamento de campo do tipo survey exploratório, que se caracteriza por avançar no conhecimento de um determinado assunto na tentativa de explicar a ocorrência de um fenômeno (FORZA, 2002), com o objetivo de quantificar uma série de práticas relativas à adoção do Programa Seis Sigma, dentre as quais evidenciar a utilização de técnicas e ferramentas como apoio ao programa. A escolha desta abordagem de pesquisa pode ser justificada em função do alcance deste tipo de abordagem no sentido da amplitude (quantidade) de empresas estudadas, possibilitando demonstrar um quadro geral de aplicação. No entanto, neste caso, não tem o objetivo de generalização dos resultados para a totalidade de empresas no país, uma vez que não se trata de um estudo probabilístico.

Embora existam estudos recentes sobre o Programa Seis Sigma no Brasil (e.g. PINTO et al., 2006; ANDRIETTA; MIGUEL, 2007; SANTOS; MARTINS, 2008) e no exterior (e.g. LEE-MORTIMER, 2007; SOLTANI; LAI, 2007), estes trabalhos não avaliam a utilização de técnicas e ferramentas no Programa Seis Sigma em profundidade, embora sejam importantes. Outros estudos realizados no país (WERKEMA, 2002; FALANDO DE QUALIDADE, 2004; CARVALHO et al., 2007) são limitados em termos de quantidade de empresas e não tratam de técnicas e ferramentas no contexto dos métodos de solução de problemas (DMAIC, DFSS e outros). Assim, o presente trabalho apresenta os resultados obtidos 
neste levantamento, tendo como foco identificar e analisar as técnicas e ferramentas utilizadas nas etapas do método DMAIC e a sua comparação com a prescrição encontrada na literatura.

\section{REFERENCIAL TEÓRICO SOBRE O PROGRAMA SEIS SIGMA}

O Programa Seis Sigma busca alcançar a excelência na competitividade por meio da melhoria dos processos produtivos. Para isso, o programa visa de maneira estruturada a melhoria contínua dos processos envolvidos na produção de um bem ou serviço, considerando todos os aspectos importantes de um negócio (HAN; LEE, 2002).

Para se alcançar este sucesso, a implantação do Programa Seis Sigma requer a aplicação sistêmica e disciplinada de técnicas e ferramentas (ANTONY et al., 2007), que auxiliam a definir os problemas e as situações que necessitam de melhoria, estabelecer procedimentos de medições com o propósito de obter dados e informações, criticar e analisar as informações coletadas, implementar as melhorias nos processos e, finalmente, controlar ou quando necessário redesenhar os processos ou produtos existentes, com o propósito de otimizá-los, proporcionando um ciclo de melhoria contínua (LUCAS, 2002).

Embora as técnicas e ferramentas não sejam nem novidade no Programa Seis Sigma ou exclusividade deste (ANTONY et al., 2007), a abordagem dada pode acrescentar considerável valor a elas, pois dissemina um vocabulário de métricas e ferramentas uniformizado em toda a organização e ainda formaliza o uso de ferramentas estatísticas, evitando-se empregá-las isolada e individualmente em aplicações distintas (HUNTER; SCHMITT, 1999).

e serviços, bem como a correlação destas com as etapas do método DMAIC.

\subsection{Classificação das técnicas e ferramentas utilizadas no Programa Seis Sigma}

A partir da revisão da literatura, poucas classificações foram encontradas para as técnicas e ferramentas empregadas no Programa Seis Sigma, sendo que See (2006) propõe uma classificação baseada em duas categorias:

- Coleta de dados e gerenciamento de análise do processo - inclui técnicas e ferramentas tais como: mapeamento do processo, matriz causa-efeito, análise dos modos e efeito das falhas (Failure Mode and Effect Analysis - FMEA) e planos de controle;

- Ferramentas de análise de processo - destaca como técnicas e ferramentas a análise e mensuração do sistema, análise da capacidade ("capabilidade") do processo, estudos multivariados, planejamento de experimentos (Design of Experiments - DOE).

Henderson e Evans (2000) descrevem a classificação realizada pela General Electric das técnicas e ferramentas, sendo que neste caso adota-se uma divisão em três grupos:

- Técnicas e ferramentas para os times de trabalho;

- Técnicas e ferramentas de processo;

- Técnicas e ferramentas estatísticas.

Segundo os autores supracitados, os dois primeiros grupos de ferramentas consistem em auxiliar na execução dos projetos no Programa Seis Sigma. O grupo de ferramentas estatísticas é empregado para identificar potenciais causas de variação em processos e, consequentemente, para reduzir esta variação e também os seus defeitos. A Tabela 1 apresenta uma classificação das técnicas e ferramentas sugeridas pelos autores citados e empregadas no Programa Seis Sigma.

Um aspecto que cabe desAacrescentar considerável valor a estas, pois dissemina um vocabulário uniformizado na organização.

Assim, considerando a importância destas técnicas e ferramentas para o sucesso do Programa Seis Sigma e para a melhoria de desempenho e consequente aumento de ganhos (INGLE; ROE, 2001), esta seção realiza uma breve revisão da literatura sobre a utilização destas no Programa Seis Sigma, os elementos chave para execução com sucesso, os métodos para seleção das técnicas e ferramentas a serem empregadas para solução de problemas, as inter-relações existentes entre as técnicas e ferramentas aplicadas no setor de manufatura plificar as categorias, pois se verifica que as técnicas e ferramentas descritas por See (2006) são, em sua maioria, simples e frequentemente empregadas no ambiente fabril, ao passo que as ferramentas citadas por Henderson e Evans (2000) são ferramentas relativamente mais complexas, necessitando de maior conhecimento e capacitação para a sua utilização.

See (2006) cita também a importância de se realizar a integração das técnicas e ferramentas ao método DMAIC, 
porém não descreve como isso deve ser feito. Em contrapartida, esta integração é apresentada por Hagemeyer et al. (2006) e é descrita mais detalhadamente no decorrer deste trabalho.

\subsection{Elementos chave para uma efetiva aplicação das técnicas e ferramentas junto ao programa Seis Sigma}

Os elementos chave correspondem aos aspectos primordiais para a implantação com sucesso de uma determinada técnica ou ferramenta, e ajudam a compreender quais pontos devem ter uma atenção especial (ANTONY; BAÑUELAS, 2002). Diversos estudos relacionados com a determinação dos elementos chave e seu nível de importância para a implantação do Programa Seis Sigma, seja no ambiente de manufatura ou de serviços, são encontrados na literatura (por exemplo em: PANDE et al., 2000; HEVERSON; EVANS, 2000; ECKES, 2000, ANTONY; BAÑUELAS, 2002). No entanto, quando se trata da determinação destes elementos chave para um efetivo emprego das técnicas e ferramentas junto ao Programa Seis Sigma poucos estudos foram realizados. Antony et al. (2007), em um destes estudos, apontam alguns elementos chave:

- Suporte e acompanhamento pela alta gerência;

- Desenvolvimento de programas de treinamento para a utilização das ferramentas;

- Envolvimento cooperativo;

- Suporte dos facilitadores;

- Disponibilidade de recursos;

- Abordagem rigorosa no gerenciamento do projeto;

- Desenvolvimento de uma tabela para indicar qual e quando utilizar uma determinada técnica ou ferramenta.
Este último elemento chave citado pelos autores pode ser auxiliado pelo emprego de uma matriz de técnicas e ferramentas, como a desenvolvida por Hagemeyer et al. (2006), e que é descrita no item a seguir.

\subsection{Método para seleção de técnicas e ferramentas}

A complexidade na resolução de problemas requer muitas vezes o uso de técnicas e ferramentas que visam auxiliar a organização na análise dos dados e informações acerca do problema. Com o intuito de facilitar esta seleção, Hagemeyer et al. (2006) desenvolveram uma matriz para ser aplicada junto ao Programa Seis Sigma. A Figura 1 ilustra de forma resumida, dada sua extensão, a matriz de seleção desenvolvida por estes autores.

Esta matriz tem como objetivo identificar, organizar e definir qual a melhor técnica ou ferramenta para a resolução de dado problema, auxiliando na solução eficaz e eficiente deste.

Segundo os autores (HAGEMEYER et al., 2006), a utilização da matriz Seis Sigma auxilia a:

- Selecionar o uso de uma técnica ou ferramenta a partir de uma série de atributos;

- Compreender a disponibilidade e propor algumas das mais comuns técnicas e ferramentas de solução de problemas;

- Identificar as técnicas ou ferramentas mais adequadas para solução de problemas de processos e entender quando aplicá-las durante o processo;

- Compreender a inter-relação e interação entre as técnicas e as ferramentas.

Para a elaboração da matriz foram selecionadas 20 técnicas e ferramentas da qualidade. Este conjunto compreende

Tabela 1: Classificação das técnicas e ferramentas utilizadas no programa Seis Sigma.

\begin{tabular}{ccc}
\hline $\begin{array}{c}\text { Técnicas e ferramentas para } \\
\text { times de trabalho }\end{array}$ & Técnicas e ferramentas de processos & Técnicas e ferramentas estatísticas \\
\hline $\begin{array}{c}\text { Fatores críticos para o sucesso } \\
\text { Lista de verificação }\end{array}$ & Brainstorming & Teste t (uma e duas amostras) \\
Gráfico inclusão/exclusão & Diagrama espinha de peixe & ANOVA \\
& Análise de Pareto & Gráfico de Box e Whisker \\
& Mapeamento do processo & Teste Qui-quadrado \\
& SIPOC (suppliers, inputs, process, outputs, customer) & Gráfico de pontos \\
& & Teste Kurskall Wallis \\
& & Plot Matrix \\
& & Gráficos de probabilidade normal \\
& & Diagrama de dispersão
\end{tabular}

Fonte: Heverson e Evans, 2000 
as ferramentas básicas da qualidade (gráficos de controle, diagrama de dispersão, matriz de causa e efeito, diagrama de Pareto, diagrama causa e efeito, folha de controle e histograma), além de outras ferramentas selecionadas pelos autores, sendo citada a análise de capabilidade, análise custo-benefício, DOE, FMEA, estudos de R\&R, teste de hipóteses, sistemas a prova de erros, análise multivariada, CEP (Controle Estatístico do Processo), mapeamento de processo e outras técnicas adicionais.

Na matriz proposta, estas vinte técnicas e ferramentas são classificadas em duas categorias principais que permitem ao usuário, por meio de uma leitura das suas características, determinar qual ou quais destas devem ser aplicadas. As categorias são:

- Caracterização da técnica ou ferramenta: descreve aspectos relativos à sua origem (por exemplo ferramenta básica da qualidade); aponta em qual(is) fase(s) do DMAIC pode ser aplicada; tipo de ferramenta (estatística, analítica ou de apoio para a organização de dados) e o nível de conhecimento (novato, intermediário ou avançado) necessário do usuário para utilizá-la.
- Atributos: esta categoria é subdividida em entradas (inputs) e saídas (outputs) necessárias para o emprego da ferramenta. Como entradas, são destacadas informações tais como: necessidades para a utilização da ferramenta (conhecimento do processo, coleta de dados, análise numérica, entre outros); necessidade do emprego anterior de outra ferramenta e com que tipo de informações a ferramenta trabalha (ideias ou números). Como saídas, são descritas as funções da ferramenta (medição, implementação, registro ou contagem), os resultados físicos resultantes (matriz, diagrama, análise numérica) e o que a ferramenta realiza com as informações concedidas (organização, priorização, classificação, comparação).

A matriz desenvolvida por Hagemeyer et al. (2006) apresenta-se como uma maneira inicial para seleção de técnicas e ferramentas a ser empregadas para solução de problemas junto ao Programa Seis Sigma. No entanto, a matriz proposta possui limitações quanto a extensão de técnicas e ferramentas e em nível de complexidade destas, já que estas

\begin{tabular}{|c|c|c|c|c|c|c|}
\hline \multicolumn{3}{|r|}{ Ferramenta } & Matriz causa e efeito & FMEA & DOE & CEP \\
\hline \multirow{4}{*}{\multicolumn{2}{|c|}{ 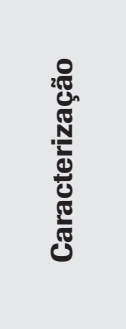 }} & Origem & Ferramenta básica & Seis Sigma & Seis Sigma & Ferramenta básica \\
\hline & & $\begin{array}{l}\text { Fase no Método } \\
\text { DMAIC }\end{array}$ & Definir/Medir & $\begin{array}{l}\text { Definir/Medir/ } \\
\text { Melhorar }\end{array}$ & Analisar/melhorar & $\begin{array}{c}\text { Medir/Analisar/ } \\
\text { Melhorar/Controlar }\end{array}$ \\
\hline & & Tipo de ferramenta & Analítica & Analítica & Estatística & Estatística \\
\hline & & $\begin{array}{l}\text { Nível de } \\
\text { conhecimento para } \\
\text { utilização }\end{array}$ & Novato & Avançado & Avançado & Intermediário \\
\hline \multirow{7}{*}{ 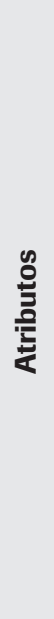 } & \multirow{3}{*}{ 遌 } & $\begin{array}{l}\text { Dados necessários } \\
\text { para uso da } \\
\text { ferramenta }\end{array}$ & Coleta de dados & Conhecimento processo & Coleta de dados & Coleta de dados \\
\hline & & $\begin{array}{l}\text { Necessidade } \\
\text { de emprego de } \\
\text { ferramenta anterior }\end{array}$ & Mapeamento processo & Mapeamento processo & Análise multivariada & Não \\
\hline & & Tipo de informação & Ideias & Ideias & Números & Números \\
\hline & \multirow{4}{*}{ ふ } & Função & Implementos & Implementos & Medição & Medição \\
\hline & & $\begin{array}{l}\text { Classificação da } \\
\text { ferramenta }\end{array}$ & Documento & Técnica & Técnica & Ferramenta \\
\hline & & Resultados & Matriz & Matriz & Matriz & Gráfico \\
\hline & & $\begin{array}{l}0 \text { que a matriz faz } \\
\text { com a informação }\end{array}$ & Organiza e classifica & $\begin{array}{c}\text { Organiza, classifica e } \\
\text { prioriza }\end{array}$ & $\begin{array}{c}\text { Organiza, classifica e } \\
\text { compara }\end{array}$ & $\begin{array}{c}\text { Provê status, prevê, } \\
\text { compara }\end{array}$ \\
\hline
\end{tabular}

Figura 1: Matriz parcial para seleção de técnicas e ferramentas junto ao programa Seis Sigma. 
são consideradas básicas para a utilização junto ao Programa Seis Sigma.

\subsection{Inter-relações entre técnicas e ferramentas aplicadas na manufatura e no setor de serviços}

Como descrito anteriormente, o Programa Seis Sigma é implementado como forma de se obter de uma maneira estruturada, a melhoria contínua dos processos envolvidos na produção de um bem ou de um serviço. No entanto, as características envolvidas em um processo de manufatura e na prestação de serviço são diferentes, sendo algumas destas diferenças apresentadas a seguir (NICOLS, 2006; ANTONY et al., 2007):

- Os dados, quando se trata de serviços, normalmente não estão disponíveis para análise e são mais difíceis de serem coletados e têm de ser coletados com interação face a face com o cliente;

- A medição da satisfação do cliente é mais difícil de ser obtida no setor de serviços;

- Dificuldade para identificação dos processos que podem ser medidos em ppm (parte por milhão) de oportunidades;

- A utilização de gráficos e fluxogramas é menos comum para o setor de serviços;

- Processos em serviços estão mais susceptíveis a ações e fatores incontroláveis;

- Uma função de transferência normalmente não está explícita nos processos em serviços, sendo mais difícil à aplicação de técnicas estatísticas;

- Muitos dos processos em serviços seguem um padrão de distribuição não normal, dificultando com isso a escolha da ferramenta correta para utilização;
- Muitas decisões no setor de serviços são tomadas por meio da intuição;

- Os processos em serviços estão muito mais dependentes das mudanças organizacionais e humanas.

A partir dessas colocações, o emprego das técnicas e ferramentas Seis Sigma na manufatura e no setor de serviços deve possuir características diferentes. Para verificar estas diferenças, foi elaborada a Tabela 2, que sintetiza os resultados obtidos da condução de dois estudos do tipo survey em empresas de manufatura e de serviços localizadas no Reino Unido (ANTONY; BAÑUELAS, 2002; ANTONY et al., 2007).

A partir da análise da Tabela 2 é possível observar que algumas técnicas e ferramentas são comumente empregadas pelo setor de serviços e manufatura, tais como: análise de Pareto, gráfico de dispersão, planejamento de experimentos (DOE), QFD e Poka Yoke. As ferramentas que possuem um cunho estatístico apresentam-se mais frequentemente quando se trata do setor de manufatura, fato este já esperado, pois neste setor a obtenção de dados dessa natureza é mais comum. Já para o setor de serviços, devido à complexa variação dos processos, as outras ferramentas, mais voltadas para a análise de dados, destacam-se como mais empregadas, pois auxiliam para a melhoria destes processos, que têm dados de natureza mais qualitativa.

\subsection{Correlação entre as ferramentas e o método DMAIC}

A aplicação do Programa Seis Sigma utiliza diversos métodos de melhorias e soluções de problemas, que de uma maneira ordenada, lógica e sistemática empregam um conjunto de ferramentas, técnicas, princípios e regras na de-

Tabela 2: Inter-relação entre ferramentas aplicadas na manufatura e setor de serviços .

\begin{tabular}{cc}
\hline Manufatura & Serviços \\
\hline Análise causa e efeito; & Mapeamento de processo; \\
Análise de Pareto; & Brainstorming; \\
Gráfico de controle; & Análise da causa raiz; \\
Gráfico de dispersão; & Gráfico de dispersão; \\
Planejamento de Experimentos (DOE); & Bencharking; \\
FMEA - Análise do modo e efeitos das falhas de Pareto; \\
QFD - Desdobramento da Função Qualidade & Ferramentas de mudança gerencial; \\
Análise de regressão & Modelo Kano; \\
Capabilidade & CEP - Controle Estatístico do Processo; \\
Poka Yoke & QFD - Desdobramento da Função Qualidade; \\
Método de Taguchi & Planejamento de Experimentos (DOE); \\
Teste de hipóteses & Análise capabilidade de processo; \\
Análise de vorrelação & Poka Yoke; \\
Custos de qualidade & Modelo Gap
\end{tabular}

Fonte: construída com base em Antony e Buñuelas, 2002; Antony et al., 2007. 
finição, elaboração, implementação, mensuração e controle dos projetos (MUNRO, 2000; GOFFNET, 2004; MALEYEFF e KRAYENVENGER, 2004).

Um desses métodos é o DMAIC, que são as iniciais para: Define (definir), Measure (medir), Analyse (analisar), Improve (melhorar) e Control (controlar). Segundo vários autores (PANDE et al., 2000; KLEFSJÖ et al., 2001; BAÑUELAS; ANTONY, 2003; LYNCH et al., 2003; GUPTA, 2005), o DMAIC é o método estruturado mais utilizado pelas empresas que aplicam o Programa Seis Sigma, bem como o mais citado nas publicações (BRADY; ALLEN, 2006), devido a sua simplicidade e similaridade com o Ciclo PDCA, que é largamente empregado no processo de melhoria contínua. Outro aspecto importante na utilização do DMAIC é o foco na satisfação do cliente (a partir das características críticas para a qualidade ou CTQs - Critical to Quality), a busca contínua da redução da variabilidade, a adaptação para o projeto de produtos e processos e a aplicação efetiva a processos administrativos e de serviços (LYNCH et al., 2003).

De acordo com Linderman et al. (2003), cada fase do método DMAIC contempla uma ação relativa a:

- Definir: é a definição clara e objetiva do projeto, compreendendo os CTQs e os requisitos técnicos, devendo ser identificados nos projetos no Programa Seis Sigma que serão desenvolvidos na empresa, com o objetivo de satisfazer as expectativas dos clientes em termos de qualidade, preço e prazo de entrega. A habilidade da organização em atender a essa expectativa está intimamente ligada à variação de seus processos (refere-se a qualquer tipo de processo, abrangendo tanto administrativos ou transacionais, como os de serviços, vendas e manufatura), como destacado por Behara et al. (1995).

- Medir: é a identificação das medidas-chave da eficiência e da eficácia transportando tais medidas para o conceito do Seis Sigma. Segundo Edgeman et al. (1999), para assegurar os resultados esperados nesta fase, são utilizadas práticas como: métricas do Seis Sigma; Análise de Sistemas de Medição (MSA); Análise de Modos de Falha e seus Efeitos (FMEA); e o Desdobramento da Função Qualidade (QFD), entre outras.

- Analisar: é a determinação das causas dos problemas que precisam de melhorias. De acordo com Eckes (2001), nesta etapa as práticas utilizadas incluem: visualização de dados; teste de hipóteses; análise de correlação e regressão; e análise de variância.

- Melhorar: é a soma das atividades relacionadas com a geração, seleção e implementação de soluções. Fundamentalmente, esta etapa consiste no desenvolvimento do planejamento de experimentos (DOE), com o objetivo de se conhecer a fundo cada processo, por meio da mudança estrutural de níveis de operação de diversos fatores, simultaneamente ao processo em estudo (BARNEY, 2002; LYNCH et al., 2003). As informações obtidas com o DOE auxiliam a identificar o ajuste das variáveis-chave para modificar e otimizar os processos.

- Controlar: é a ação de garantir que as melhorias se sustentem ao longo do tempo. Young (2001) enfatiza que dentre as práticas adotadas nesta fase destacam-se: cartas de controle; planos de controle; testes de confiabilidade e processos à prova de erros.

A Tabela 3, elaborada por Hagemeyer et al. (2006), apresenta a relação existente entre as etapas do método DMAIC e algumas técnicas e ferramentas empregadas em Programas Seis Sigma.

O presente trabalho tem como um de seus objetivos confrontar os aspectos descritos na literatura com dados empíricos, advindos de empresas que adotam o Programa Seis Sigma no país, com o intuito de realizar uma inter-relação entre os elementos teóricos e os elementos empíricos, sendo que para isso foi conduzido um levantamento tipo survey, pormenorizado a seguir.

\section{MÉTODOS E TÉCNICAS DA PRESENTE PESQUISA}

Antes do presente estudo foram realizados outros três levantamentos sobre a aplicação do Programa Seis Sigma no Brasil. O trabalho de Werkema (2002) enviou questionário para 25 empresas brasileiras obtendo uma taxa de retorno de $44 \%$, ou seja, com 11 empresas participantes. O outro levantamento (FALANDO DE QUALIDADE, 2004) foi realizado via e-mail para 795 contatos, de um banco de dados de 986, com o retorno de 191. Somados os respondentes que efetivamente preencheram o questionário por $e$-mail e aqueles que fizeram contatos por telefone, foram coletadas 100 respostas efetivas, mas apenas 8 empresas utilizavam o Programa Seis Sigma. Um último levantamento recente sobre o estado de difusão e implantação do Seis Sigma no Brasil foi apresentado por Carvalho et al. (2007), no qual foram enviados aproximadamente 1.000 questionários, sendo obtidos 198 questionários válidos, tendo porém 46 organizações que responderam que haviam implementado o Programa Seis Sigma.

Já o presente estudo foi desenvolvido a partir de um levantamento cujo objetivo foi quantificar uma série de práticas relativas à adoção do Programa Seis Sigma, dentre as quais, evidenciar a utilização de técnicas e ferramentas como apoio ao programa. Este levantamento caracteriza-se como do tipo survey, conforme a classificação de Malhotra e Grover (1998). 
Como o trabalho foi desenvolvido por meio de um levantamento realizado junto a empresas que confirmaram a utilização do Programa Seis Sigma e ainda teve a intenção de confirmar se são válidos os dados divulgados na literatura existente sobre o assunto, o levantamento caracteriza-se como uma survey exploratória-descritiva, pois este tipo de pesquisa tem por objetivo avançar no conhecimento de um determinado assunto na tentativa de explicar a ocorrência de um fenômeno (FORZA, 2002), não tendo características, portanto, de uma survey de teste de teoria.

Os dados foram coletados por meio de um questionário enviado para 121 empresas que asseguraram previamente (via consulta por telefone) que aplicavam o Programa Seis Sigma. Assim, o conjunto de empresas foi definido, valendo-

Tabela 3: Associação das técnicas e ferramentas Seis Sigma às etapas do DMAIC.

\begin{tabular}{|c|c|c|c|c|c|}
\hline \multirow[t]{2}{*}{ Técnicas e Ferramentas } & \multicolumn{5}{|c|}{ Utilização junto ao DMAIC } \\
\hline & Definir & Medir & Analisar & Melhorar & Controlar \\
\hline Análise de regressão & & & $\mathrm{x}$ & & \\
\hline Análise de stakeholder & $x$ & & & $x$ & \\
\hline Benchmarking & & & $x$ & & \\
\hline Brainstorming & & & $\mathrm{x}$ & $x$ & \\
\hline Cartas de controle & & $x$ & $x$ & $x$ & $x$ \\
\hline Plano de negócio & $x$ & & & & \\
\hline Consenso & & & & $x$ & \\
\hline Controle Estatístico do Processo & & & & $x$ & $x$ \\
\hline CTQ (árvore crítica da qualidade) & $x$ & & & & \\
\hline Diagrama de afinidades & $\mathrm{x}$ & & $x$ & & \\
\hline Diagrama de causa e efeito & & & $\mathrm{x}$ & & \\
\hline Diagrama de Pareto & & $x$ & $x$ & $x$ & \\
\hline Estratificação & & $\mathrm{x}$ & $\mathrm{x}$ & $\mathrm{x}$ & $\mathrm{x}$ \\
\hline Ferramentas de planejamento & & & & $x$ & \\
\hline Fluxograma & $\mathrm{x}$ & $\mathrm{x}$ & $x$ & $x$ & $\mathrm{x}$ \\
\hline FMEA & & $\mathrm{x}$ & & $x$ & $x$ \\
\hline Folha de verificação & & & & $x$ & $\mathrm{x}$ \\
\hline Estudos de R\&R & & $\mathrm{x}$ & & & \\
\hline Gráficos de controle de processo & & & & & $\mathrm{x}$ \\
\hline Gráfico de frequência & & $\mathrm{x}$ & $\mathrm{x}$ & $\mathrm{x}$ & $\mathrm{x}$ \\
\hline Gráfico de priorização & & $\mathrm{x}$ & & $x$ & \\
\hline Gráfico de dispersão & & & $x$ & & \\
\hline Índices de capabilidade & & $x$ & & $x$ & \\
\hline Modelo de Kano & & $x$ & & & \\
\hline Planejamento de experimentos & & & $x$ & $x$ & $x$ \\
\hline Plano de controle & & & & $x$ & $\mathrm{x}$ \\
\hline Poka Yoke & & & & $x$ & $x$ \\
\hline Procedimento operacional padrão & & & & & $x$ \\
\hline Simulação & & & & $x$ & $x$ \\
\hline SIPOC & $x$ & & & & \\
\hline Técnica de coleta de dados & & $\mathrm{x}$ & $\mathrm{x}$ & $x$ & $x$ \\
\hline Técnicas de amostragem & & $\mathrm{x}$ & $x$ & $x$ & $x$ \\
\hline Séries temporais & & $x$ & & & \\
\hline Teste de hipóteses & & & $\mathrm{x}$ & & \\
\hline Voz do cliente & $x$ & & & & \\
\hline
\end{tabular}

Fonte: Hagemeyer et al., 2006. 
se de fontes variadas, tais como: buscas em sites de empresas, verificação em revistas especializadas nas áreas de qualidade e gestão, levantamento junto às empresas de consultoria $e$ serviços; consultas aos fóruns e entidades associativas de empresas; e a participação em cursos e seminários. Considerando que a pesquisa teve por objetivo uma extensa abrangência territorial no país, esta amostra não probabilística mostrou-se adequada, principalmente tendo em vista a viabilidade operacional requerida para a conquista de resultados satisfatórios, conforme destaca Mattar (1996).

$\mathrm{O}$ instrumento de coleta de dados escolhido para a realização da pesquisa foi um questionário, com a maior parte de questões fechadas (pela facilidade de tabulação), pois este instrumento possibilita a racionalização do tempo de preenchimento do respondente, facilita a aplicação simultânea em várias empresas, consegue atingir maior abrangência territorial e confere o caráter de sigilo, propiciando privacidade aos respondentes, que preenchem a pesquisa sem riscos de constrangimentos (MARCONI; LAKATOS, 1996). O questionário também considerou um glossário dos termos técnicos utilizados no decorrer do instrumento.

\section{$\Delta s$ técnicas e ferramentas comuns a todas as Aetapas são as mais utilizadas em razão de preferência ou de maior domínio.}

Após o retorno dos questionários, os dados foram tabulados seguindo a lógica das questões, sendo elaborados gráficos que subsidiam a apresentação e análise dos resultados, os quais são apresentados a seguir. É importante destacar ainda que a análise dos dados foi baseada no referencial teórico desenvolvido, no sentido de corroborar ou não os dados e informações da literatura.

Este trabalho apresenta e analisa os resultados obtidos na pesquisa restringindo-se em abordar os resultados relativos do uso das técnicas e ferramentas utilizadas pelas empresas que aplicam o Programa Seis Sigma no território nacional. No entanto, como citado na Introdução, os resultados não têm como objetivo a sua generalização, uma vez que a amostra é intencional e, portanto, não probabilística.

\section{APRESENTAÇÃO E ANÁLISE DOS RESULTADOS}

Os dados apresentados são resultantes da devolução de 78 questionários preenchidos dos 121 que foram enviados, registrando-se uma taxa de retorno de $64,5 \%$. A localização das empresas no país é mostrada na Figura 2, e se concen- tram no Estado de São Paulo (64,1\%), Minas Gerais (8,9\%), Amazonas (6,4\%), Rio Grande do Sul (5,1\%), Rio de Janeiro (3,4\%), Santa Catarina (3,8\%), Espírito Santo (1,3\%), Paraíba $(1,3 \%)$ e Pernambuco $(1,3 \%)$. Esta distribuição é muito similar ao direcionamento dos questionários. $\mathrm{O}$ fato da maior parte das empresas respondentes serem oriundas do Estado de São Paulo se dá em função da própria população-alvo e também porque grande parte das empresas usuárias do Programa Seis Sigma, estavam localizadas neste Estado quando da condução da pesquisa.

\subsection{Caracterização das empresas que aplicam o Programa Seis Sigma}

Os setores industriais das empresas respondentes são apresentados na Figura 3, conforme os critérios da revista Exame (2005). Nota-se que o setor automotivo destacou-se entre os respondentes com um percentual de $37 \%$, seguindose pelo segmento eletroeletrônico, com cerca de $19 \%$.

O levantamento também traçou o perfil das empresas quanto ao porte com base nos critérios do PNQ - Prêmio Nacional da Qualidade (FNQ, 2004), segundo o número de funcionários (empresas pequenas: até 50 ; médias: de 51 a 500; grandes: mais de 500). A partir desse critério, os dados coletados constataram que $65,4 \%$ das empresas analisadas são de grande porte e $34,6 \%$ são empresas médias. Cabe ressaltar que, apesar da literatura indicar que o Seis Sigma pode ser utilizado por empresas de qualquer tamanho, como destacam algumas publicações (PFEIFER et al., 2004; WESSEL; BURCHER, 2004), este fato não foi verificado no presente trabalho, haja vista a ausência de micro e pequenas empresas entre as respondentes, bem como na população estudada.

Em relação ao indicador de faturamento anual, constatouse que as empresas estudadas apresentaram faixas variando desde $\mathrm{R} \$ 33$ milhões a R 18 bilhões. Assim, considerando-se o ranking da revista Exame (2005), mais de 60\% das empresas respondentes estão entre as 500 maiores empresas em faturamento anual no Brasil.

\section{RESULTADOS E DISCUSSÃO}

A lista de técnicas e ferramentas utilizadas nas etapas do método DMAIC do questionário continha 58 técnicas e ferramentas e, para cada uma, o respondente assinalava, em uma tabela construída com base na literatura, qual (ou quais) etapa(s) do método DMAIC a técnica ou a ferramenta é utilizada. Cabe destacar que no questionário foi inserido um glossário com o significado das 58 técnicas e ferramentas 
relacionadas. A tabulação da planilha é mostrada na Tabela 4 , onde consta o percentual de empresas que indicaram o uso das ferramentas e técnicas em cada etapa do DMAIC. A Tabela 4 foi elaborada considerando a ordem de emprego (ranking) das ferramentas em função da média de utilização pelas etapas do método DMAIC (todas), sendo que as 10 técnicas e ferramentas mais utilizadas em cada etapa do DMAIC são indicadas na cor cinza escuro e as 10 menos utilizadas na cor cinza claro. No Apêndice, esta tabela é apresentada por completo.

As distribuições da utilização das técnicas e ferramentas em cada etapa do método DMAIC mostram-se bastante uniformes, pois foi testada a normalidade, que indicou uma curva normal e assintótica negativa (média maior que a mediana). Foi realizado também o cálculo de duas medidas de dispersão (desvio padrão e coeficiente de variação) que se apresentaram elevados, porém dentro de padrões aceitáveis e que permitem a realização da análise proposta inicialmente no objetivo deste trabalho sem, portanto, um aprofundamento estatístico.

Vale destacar que, de um rol extenso de técnicas e ferramentas, ao redor de $15 \%$ delas são as mais utilizadas em todas as etapas do método DMAIC. Isso se deve ao fato de que existem técnicas e ferramentas que se mostram apropriadas para uma etapa e não para outras. Porém, aparentemente as técnicas e ferramentas comuns a todas as etapas seriam mais utilizadas em razão de preferência ou de maior domínio

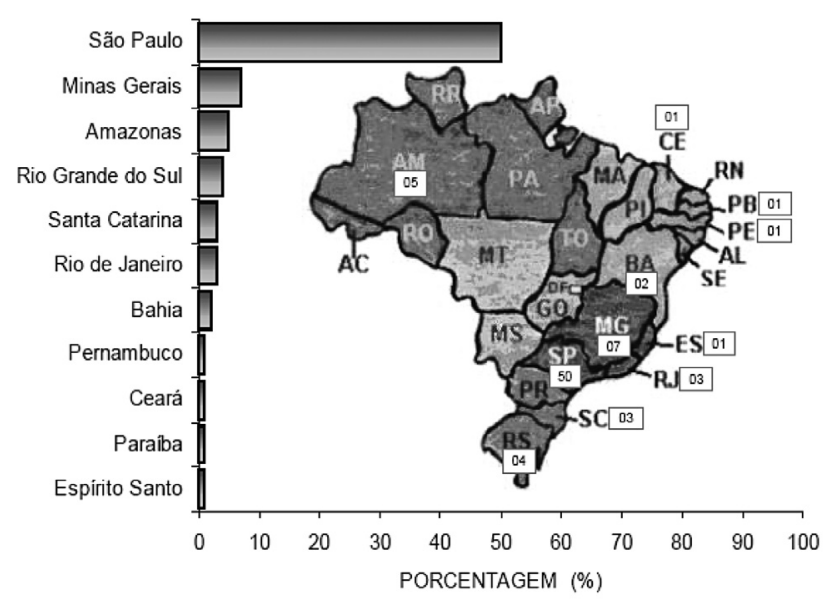

Figura 2: Localização geográfica das empresas respondentes. (conhecimento, habilidade e facilidade de uso) pelos participantes do Programa Seis Sigma das empresas respondentes. No entanto, esse é um aspecto que não foi possível de ser confirmado na presente investigação.

As Figuras 4 e 5 ilustram, graficamente, os respectivos percentuais acumulados das empresas respondentes para as ferramentas mais usadas e as menos usadas.

\section{programa Seis Sigma necessita de dados mensuráveis e confiáveis, evidenciando que o emprego das técnicas e ferramentas é indispensável.}

Os resultados revelaram que as dez técnicas e ferramentas mais utilizadas pelas empresas pesquisadas e que aplicam o método DMAIC no Programa Seis Sigma são: coleta de dados, histograma, diagrama de Pareto, brainstorming, carta de controle, índices de capacidade, fluxograma, mapa de processo, avaliação do sistema de medição e CEP.

Os dados coletados no presente trabalho indicaram também que oito das dez técnicas e ferramentas mais usadas no DMAIC estão concentradas na etapa "Medir" do método. Tal ocorrência pode ser explicada em função de que nesta fase são aplicadas as ferramentas que medem o desempenho dos processos, e que, assim, permitem uma visualização do estado atual dos mesmos para a definição das metas de aprimoramento, como destacam alguns autores (BREYFOGLE III et al., 2001; MCADAM; LAFFERTY, 2004).

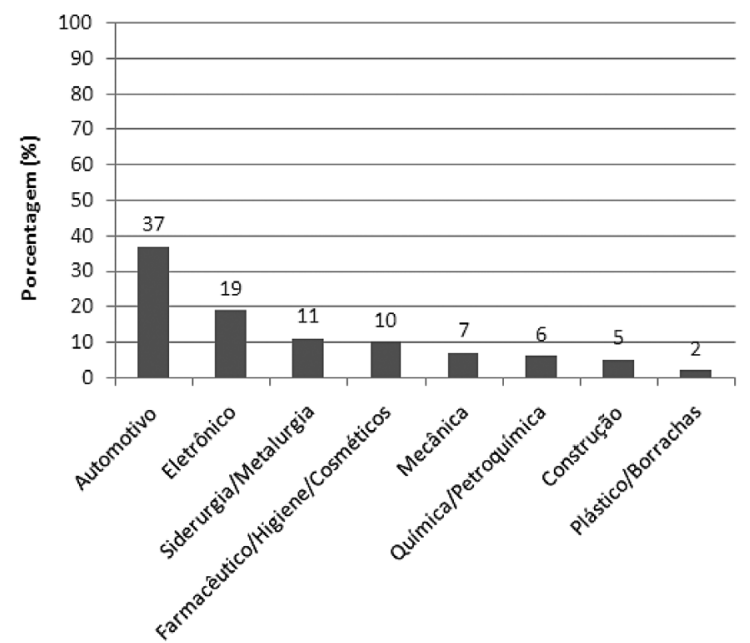

Figura 3: Setor de atividade econômica das empresas respondentes. 
No estudo conduzido por Hahn et al. (2000) também foram identificadas as dez ferramentas mais utilizadas no Programa Seis Sigma, a saber: cartas de controle, histograma, diagrama de Pareto, diagrama de causa e efeito, matriz de causa e efeito, gráfico box plot, estudo de análise multivariada, teste de hipóteses para médias e para variâncias e gráficos de controle por variáveis. Comparando-se os dados do presente trabalho com o que foi realizado por Hahn et al. (2000), apenas três ferramentas e técnicas usadas no Programa Seis Sigma estão presentes nos dois estudos: cartas de controle, histograma e diagrama de Pareto.

Comparando-se os resultados deste levantamento com outro realizado por Antony e Bañuelas (2002), que também identificaram as dez ferramentas mais utilizadas no Programa Seis Sigma (análise de causa e efeito, cartas de controle, diagrama de Pareto, mapa de processo, planejamento de experimentos, FMEA, índices de capabilidade, QFD, análise de regressão e teste de hipóteses) observa-se que existe uma coincidência na utilização de quatro delas (cartas de controle, diagrama de Pareto, índices de capacidade e mapa de processo).

A Figura 5 apresenta as ferramentas menos usadas em cada etapa do DMAIC, indicadas pelas empresas respondentes.

Os resultados do presente levantamento (Figura 5) quando relacionados com as dez ferramentas menos utilizadas no método DMAIC (OCAP, PDPC, operação evolutiva, teste de operação, PERT/CPM, teste de mercado, Stakeholder Analysis, FTA e teste de vida acelerada) ao ser comparado com o estudo de Antony e Bañuelas (2002), que também aponta as técnicas e ferramentas menos utilizadas nos Programas Seis Sigma (método Taguchi, CEP e sistema à prova de erros), demonstram que quando comparadas com o presente levantamento não são coincidentes. Segundo Antony e Bañuelas (2002), as técnicas e ferramentas "mais poderosas" são menos usadas pelas organizações. O termo "mais poderosas"

Tabela 4: Dez (10) técnicas e ferramentas da qualidade mais e menos utilizadas nas etapas do método DMAIC em \% de respondentes.

\begin{tabular}{|c|c|c|c|c|c|c|c|}
\hline \multirow[t]{2}{*}{ TÉCNICAS E FERRAMENTAS } & \multicolumn{7}{|c|}{ Etapa do Método DMAIC } \\
\hline & Definir & Medir & Analisar & Melhorar & Controlar & Todas & Ranking \\
\hline Técnicas de Coleta de Dados & 55,13 & 89,74 & 46,15 & 34,62 & 34,62 & 52,05 & 1 \\
\hline Histograma & 33,33 & 74,36 & 67,95 & 28,21 & 37,18 & 48,21 & 2 \\
\hline Diagrama de Pareto & 57,69 & 64,10 & 64,10 & 25,64 & 26,92 & 47,69 & 3 \\
\hline Brainstorming & 65,38 & 38,46 & 61,54 & 44,87 & 17,95 & 45,64 & 4 \\
\hline Cartas de Controle & 19,23 & 50,00 & 50,00 & 29,49 & 75,64 & 44,87 & 5 \\
\hline Índices de Capacidade & 26,92 & 57,69 & 47,44 & 39,74 & 48,72 & 44,10 & 6 \\
\hline Fluxograma & 60,26 & 51,28 & 46,15 & 34,62 & 20,51 & 42,56 & 7 \\
\hline Mapa de Processo & 55,13 & 46,15 & 50,00 & 34,62 & 16,67 & 40,51 & 8 \\
\hline Avaliação de Sistemas de Medição/Inspeção & 14,10 & 83,33 & 38,46 & 33,33 & 25,64 & 38,97 & 9 \\
\hline Controle Estatístico de Processo & 15,38 & 41,03 & 37,18 & 28,21 & 70,51 & 38,46 & 10 \\
\hline Stokeholder Analysis & 29,49 & 7,69 & 6,41 & 8,97 & 3,85 & 11,28 & 49 \\
\hline Teste de Vida Acelerada & 0,00 & 11,54 & 25,64 & 10,26 & 5,13 & 10,51 & 50 \\
\hline FTA & 2,56 & 6,41 & 30,77 & 7,69 & 3,85 & 10,26 & 51 \\
\hline Stokeholder & 29,49 & 6,41 & 1,28 & 6,41 & 3,85 & 9,49 & 52 \\
\hline Teste de Mercado & 5,13 & 11,54 & 14,10 & 11,54 & 5,13 & 9,49 & 53 \\
\hline PERT/CPM & 8,97 & 8,97 & 3,85 & 14,10 & 2,56 & 7,69 & 54 \\
\hline Teste de Operação & 2,56 & 5,13 & 14,10 & 14,10 & 2,56 & 7,69 & 55 \\
\hline Operação Evolutiva & 2,56 & 5,13 & 11,54 & 15,38 & 2,56 & 7,44 & 56 \\
\hline PDPC & 3,85 & 7,69 & 6,41 & 10,26 & 1,28 & 5,90 & 57 \\
\hline OCAP & 0,00 & 3,85 & 5,13 & 5,13 & 12,82 & 5,38 & 58 \\
\hline
\end{tabular}


(extraído da literatura) é considerado neste trabalho como aquelas ferramentas que propiciam resultados mais robustos e são, geralmente, mais complexas. Estas ferramentas podem significar, por exemplo, que metodologicamente são mais estruturadas, como o QFD ou métodos estatísticos que, por si sós, podem corresponder a uma área de estudo como o planejamento de experimentos.

Por fim, vale mencionar que os levantamentos realizados anteriormente (WERKEMA, 2002; FALANDO DE QUALIDADE, 2004; CARVALHO et al., 2007) não trataram da abordagem referente à utilização dos chamados "métodos de solução de problemas" (DMAIC, DFSS e outros) ou ainda, das técnicas e ferramentas que são utilizadas nas etapas do método DMAIC.

Buscando confrontar se o emprego das técnicas e ferramentas no Programa Seis Sigma pelas empresas respondentes condiz com a proposta de Hagemeyer et al. (2006) para aplicação destas junto às etapas do método DMAIC, foi construída a Tabela 6. Em cinza escuro estão destacadas as 10 ferramentas mais utilizadas e em cinza claro as dez ferramentas menos utilizadas, considerando as etapas do método DMAIC. Para as técnicas e ferramentas comuns entre a proposta realizada por Hagemeyer et al. (2006) foram assinaladas (com um "X") as etapas do DMAIC nas quais os autores sugerem a sua aplicação.

Por meio da análise da Tabela 6 é possível verificar que o emprego das técnicas e ferramentas, nas empresas no país, encontra-se em mais etapas do método DMAIC do que a proposta realizada por Hagemeyer et al. (2006). Isto vem indicar que as técnicas e ferramentas podem ser empregadas em todas as etapas do processo, ajudando a promover soluções que levem à melhoria contínua.

\section{CONCLUSÕES}

O trabalho buscou enfatizar a utilização das técnicas e ferramentas empregadas nas empresas instaladas no Brasil que aplicam o Programa Seis Sigma. Nesse sentido, foram apresentados os resultados de um levantamento do tipo survey exploratória realizada com a finalidade de levantar uma série de práticas relativas ao programa, dentre elas a utilização das técnicas e ferramentas, foco do presente trabalho.

Com o objetivo de confrontar aspectos relatados na li-

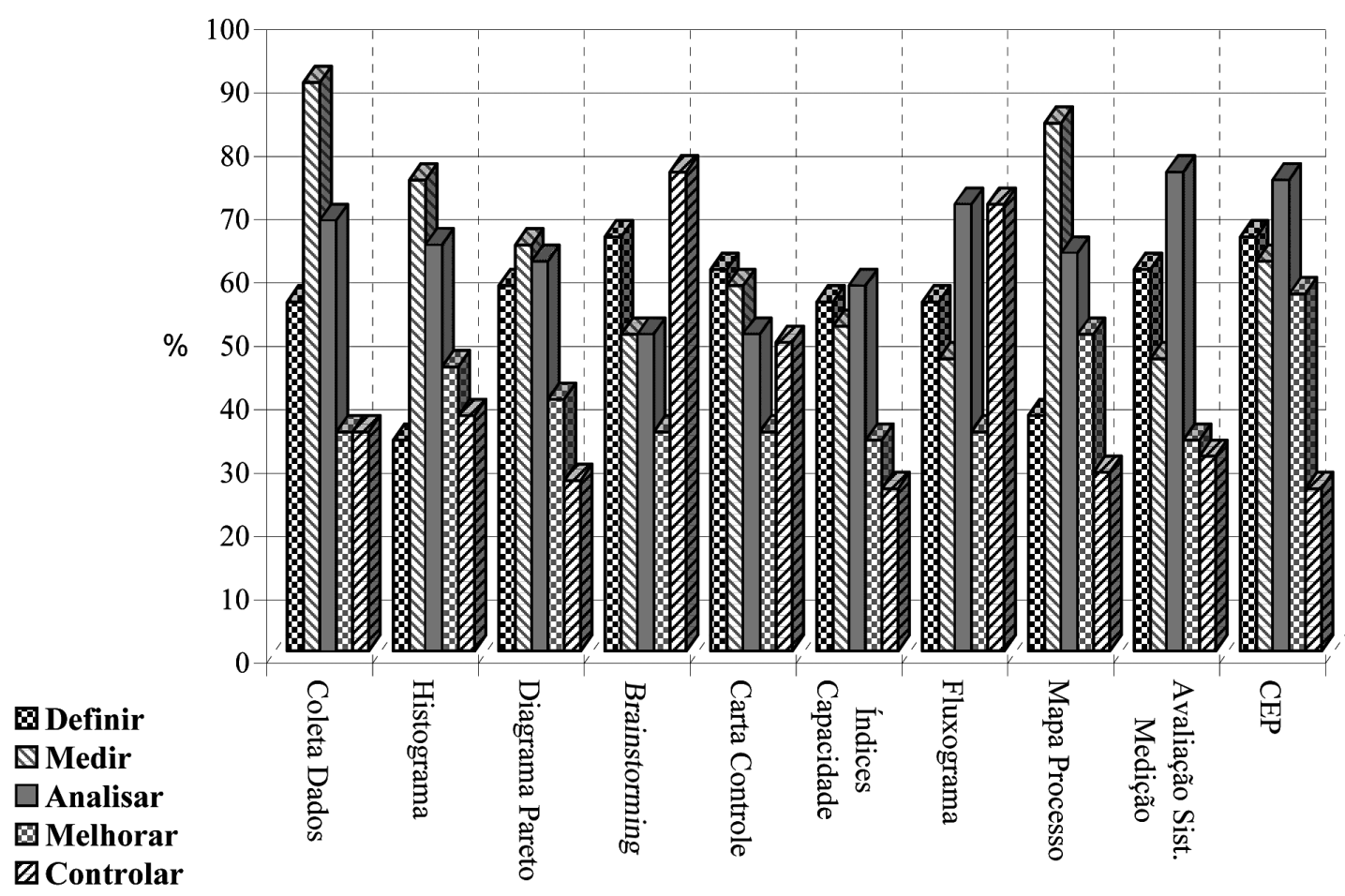

Figura 4: As 10 técnicas e ferramentas mais utilizadas no método DMAIC. 
teratura, foi realizada uma revisão de literatura destacando diversos aspectos relativos à aplicação das técnicas e ferramentas do Programa Seis Sigma.

Os resultados do trabalho de campo possibilitaram a tabulação de 58 técnicas e ferramentas que podem ser usadas em cada uma das cinco etapas do método DMAIC. A obtenção destes dados permitiu a realização da comparação com diversos estudos que identificam técnicas e ferramentas mais e menos empregadas pelas empresas. Verificou-se que são poucas as técnicas e ferramentas coincidentes quando se trata das mais empregadas, ao passo que quando se analisam as técnicas e ferramentas menos empregadas, estas não possuem nenhuma relação.

Outra comparação que cabe ser aqui destacada é a associação das técnicas e ferramentas do Programa Seis Sigma e as etapas do DMAIC identificada na literatura. A comparação desta com os resultados obtidos no levantamento per- mite observar que as empresas estão empregando as técnicas e ferramentas em mais etapas do método DMAIC do que o proposto por estes autores. Isto indica que nenhuma classificação pode ser tomada como única ou verdadeira, nem de que esta classificação seja a mais completa ou singular.

Cabe destacar que a pesquisa confirmou os indicativos do referencial teórico, os quais apontam pela necessidade do Programa Seis Sigma se apoiar em dados mensuráveis e confiáveis, a partir de suas técnicas e ferramentas, evidenciando assim que no método DMAIC o emprego das técnicas e ferramentas é praticamente indispensável.

Insere-se ainda nesta discussão a possibilidade de se realizar futuramente uma análise estatística mais detalhada e aprofundada dos resultados obtidos, tarefa esta não realizada por divergir escopo do presente trabalho, que se propôs evidenciar sobre diversos aspectos a utilização de técnicas e ferramentas como apoio ao Programa Seis Sigma.

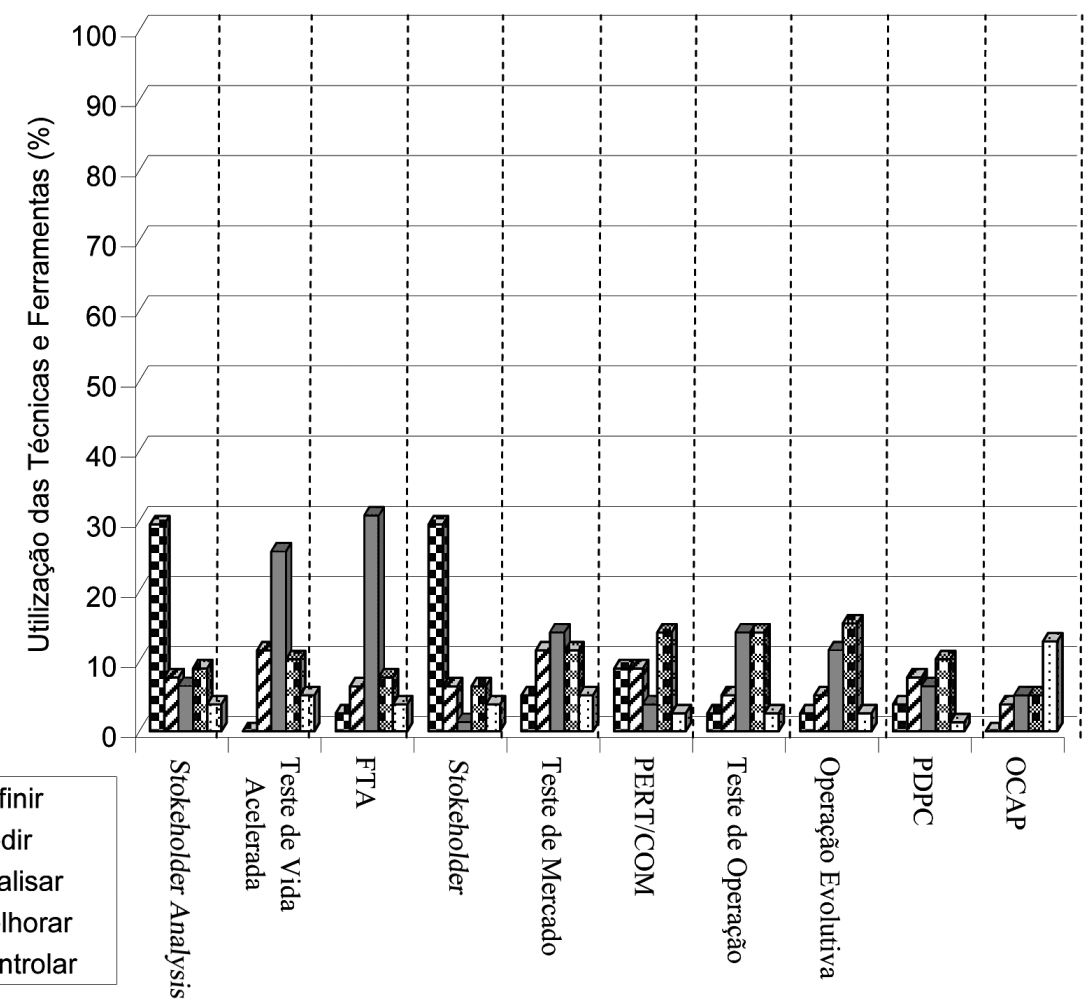

Técnicas e Ferramentas

Figura 5: As 10 técnicas e ferramentas menos utilizadas no método DMAIC 
Tabela 6: Técnicas e ferramentas da qualidade utilizadas nas etapas do método DMAIC em \% de respondentes.

\begin{tabular}{|c|c|c|c|c|c|}
\hline \multirow[t]{2}{*}{ TÉCNICAS E FERRAMENTAS } & \multicolumn{5}{|c|}{ Etapa do método DMAIC } \\
\hline & Definir & Medir & Analisar & Melhorar & Controlar \\
\hline Técnicas de Coleta de Dados & & $x$ & $\mathrm{X}$ & $x$ & $\mathrm{X}$ \\
\hline \multicolumn{6}{|l|}{ Histograma } \\
\hline Diagrama de Pareto & & $x$ & $\mathrm{X}$ & $x$ & \\
\hline Brainstorming & & & $\mathrm{X}$ & $x$ & \\
\hline Cartas de Controle & & $x$ & $x$ & $x$ & $x$ \\
\hline Índices de Capacidade & & $x$ & & $x$ & \\
\hline Fluxograma & $x$ & $x$ & $x$ & $x$ & $x$ \\
\hline \multicolumn{6}{|l|}{ Mapa de Processo } \\
\hline \multicolumn{6}{|l|}{ Avaliação de Sistemas de Medição/Inspeção } \\
\hline Controle Estatístico de Processo & & & & $x$ & $\mathrm{x}$ \\
\hline \multicolumn{6}{|l|}{ Mapeamento do Processo } \\
\hline FMEA & & $x$ & & $x$ & $\mathrm{x}$ \\
\hline \multicolumn{6}{|l|}{ Mapa de Raciocínio } \\
\hline Diagrama de Causa e Efeito & & & $x$ & & \\
\hline \multicolumn{6}{|l|}{ Análise Econômica } \\
\hline \multicolumn{6}{|l|}{ Boxplot } \\
\hline \multicolumn{6}{|l|}{ Análise de Variância } \\
\hline Voz do Cliente & $x$ & & & & \\
\hline Análise de Causa Raiz & & & $x$ & & \\
\hline \multicolumn{6}{|l|}{ Teste de Hipóteses } \\
\hline Planejamento de Experimentos & & & $\mathrm{X}$ & $X$ & $X$ \\
\hline \multicolumn{6}{|l|}{ Análise Multivariada } \\
\hline \multicolumn{6}{|l|}{ Diagrama de Relações } \\
\hline Diagrama de Afinidades & $\mathrm{x}$ & & $x$ & & \\
\hline \multicolumn{6}{|l|}{ Relatório de Anomalias } \\
\hline \multicolumn{6}{|l|}{ Carta Multi-Van } \\
\hline \multicolumn{6}{|l|}{ Diagrama de Matriz } \\
\hline Stakeholder Analysis & $x$ & & & $x$ & \\
\hline \multicolumn{6}{|l|}{ Ensaio de Vida Acelerada } \\
\hline \multicolumn{6}{|l|}{ FTA } \\
\hline \multicolumn{6}{|l|}{ Teste de Mercado } \\
\hline \multicolumn{6}{|l|}{ PERT/CPM } \\
\hline \multicolumn{6}{|l|}{ Teste de Operação } \\
\hline \multicolumn{6}{|l|}{ Operação Evolutiva } \\
\hline \multicolumn{6}{|l|}{ PDPC } \\
\hline OCAP & & & & & \\
\hline
\end{tabular}




\section{Artigo recebido em 21/06/2007 Aprovado para publicação em 07/05/2009}

\section{REFERÊNCIAS}

ANDRIETTA, J. M.; MIGUEL, P. A. C. Aplicação do programa seis sigma no Brasil: resultados de um levantamento tipo survey exploratório-descritivo e perspectivas para pesquisas futuras. Gestão \& Produção, v. 14, n. 2, p. 203-219, 2007.

ANTONY, J.; ANTONY, F. J.; KUMAR, M.; $\mathrm{CHO}$, B. R. Six Sigma in service organizations. International Journal of Quality \& Reliability Management, v. 24, n. 3, p. 294-311, 2007.

ANTONY, J.; BAÑUELAS, R. Key ingredients for the effective implementation of Six Sigma program. Measuring Business Excellence, v. 6, n. 4 , p. 20-27, 2002

BAÑUELAS, R.; ANTONY, J. Going from Six Sigma to design for six sigma: an exploratory study using analytic hierarchy process. The TQM Magazine, v. 15, n. 5, p. 334-344, 2003.

BARNEY, M. Motorola's Second Generation. Six Sigma Forum Magazine, v. 1, n. 3, p. 13-16, 2002.

BEHARA, R. S.; FONTENOT, G. F.; GRESHAM, A. Customer satisfaction measurement and analysis using Six Sigma. International Journal of Quality \& Reliability Management, v. 12, n. 3 , p. 9-18, 1995

BRADY, J. E.; ALLEN, T. T. Six sigma literature: a review and agenda for future research. Quality and Reliability Engineering International, v. 22, p. 335-367, 2006.

BREYFOGLE III, F. W.; CUPELLO J. M.; MEADOWS, B. Managing Six Sigma: a practical guide to understanding, assessing, and implementing the strategy that yields bottomline success. New York: John Wiley \& Sons, Inc., 2001.

CARVALHO, M. M.; HO, L. L.; PINTO, S. B. Implementação e difusão do programa Seis Sigma no Brasil. Produção, v. 17, n. 3, p. 486501, 2007.

COOPER, P. C.; NOONAN, P. Do Teams and Six Sigma Go Together? Quality Progress, v. 36, n. 6, p. 25-28, 2003.

ECKES, G. The Six sigma Revolution. New York: John Wiley \& Sons, 2000.
ECKES, G. The Six Sigma revolution: how General Electric and others turned process into profits. New York: John Wiley \& Sons, 2001.

EDGEMAN, R. L.; DAHLGAARD, S. M. P.; DAHLGAARD, J. J.; SCHERER, F. On leaders and leadership. Quality Progress, v. 32, n.10, p. 49-54, 1999

EXAME. Melhores e Maiores 2005. São Paulo: Editora Abril. Edição Especial, julho, 2005.

FALANDO DE QUALIDADE. Pesquisa: A realidade do Seis Sigma no Brasil. São Paulo: Editora EPSE, ano XIII, n. 144, p. 31-40, 2004.

FOLARON, J. The Evolution of Six Sigma. Six Sigma Forum Magazine, v. 2, n. 4, p. 35-45, 2003.

FORZA, C. Survey research in operations management: a process-based perspective. International Journal of Operations \& Production Management, v. 22, n. 2, p. 152-194, 2002.

GOFFNET, S. P. Understanding Six Sigma Implications for Industry and Education. Journal of Industrial Technology, v. 20, n. 4, p. 2- 10, 2004.

GUPTA, P. Innovation: the key to a successful project. Six Sigma Forum Magazine, v. 4, n. 4. p. 13-17, 2005

HAGEMEYER. C.; GERSHENSON, J. K.; JOHNSON, D. M. Classification and application of problem solving quality tools. The TQM Magazine, v. 18, n. 5, p. 455-483, 2006.

HAHN, G. J.; DOGONAKSOY, N.; HOERL, R. The evolution of Six Sigma. Quality Engineering v. 12 , n. 3 , p. $317-326,2000$.

HAN, C.; LEE, Y. H. Intelligent integrated plant operation system for Six Sigma. Annual Reviews Control, v. 26, p. 27-43, 2002.

HENDERSON, M. H.; EVANS, J. R. Successful implementation of Six Sigma: benchmarking General Electric Company. Benchmarking An International Journal, v. 7, n. 4 p. 260-281, 2000.
HUNTER, D.; SCHMITT, B. Six Sigma: benefits and approaches. Chemical Week, v. 161, n. 37, p. 35-36, 1999.

INGLE, S.; ROE, W. Six Sigma black belt implementation. The TQM Magazine, v. 13, n. 4, p. 273-280, 2001.

KLEFSJÖ, B.; WIKLUND, N.; EDEGMAN, R. L. Six Sigma seen as a methodology for total quality management. Measuring Business Excellence, v. 5, n.1, p. 31-35, 2001.

LAI, P. C.; SOLTANI, E. Approaches top quality management in the UK: survey evidence and implications. Benchmarking: An International Journal, v. 14, n. 4, p. 429-454, 2007.

LEE-MORTIMER, A. Leading UK manufacturer probes the potential of six sigma. Journal of Assembly Automation, v. 27, n. 4, p. 302-308, 2007.

LINDERMAN, K.; SCHROEDER, R. G.; ZAHEER, S.; CHOO, A. S. Six Sigma: a goal-theoretic perspective. Journal of Operations Management, v. 3, n. 21, p. 193-203, 2003.

LUCAS, J. M. The essential Six Sigma. Quality Progress, v. 31, n. 1, p. 27-31, 2002.

LYNCH, D. P.; BERTOLINE, S.; CLOUTIER, E. How to scope DMAIC projects. Quality Progress, v. 36, n. 1, p. 37-41, 2003.

MALEYEFF, J.; KRAYENVENGER, D. E. Goal setting with Six Sigma mean shift determination. Aircraft Engineering and Aerospace Technology, v. 76, n. 6, p. 577-583, 2004.

MALHOTRA, N. K; GROVER, V. An assessment of survey research in POM: from constructs to theory. Journal of Operations Management, v. 16 , n. 17, p. 407-425, 1998.

MARCONI, M. D. A.; LAKATOS, E. M. Técnicas de pesquisa: planejamento e execução de pesquisas, amostragens e técnicas de pesquisas, elaboração, análise e interpretação de dados. 3. Ed. São Paulo: Atlas, 1996.

MATTAR, F. N. Pesquisa de marketing: edição compacta. São Paulo: Atlas, 1996. 
MCADAM, R.; LAFFERTY, B. A multilevel case study critique of Six Sigma: statistical control of strategic change? International Journal of Operations \& Production Management, v. 24, n. 5, p. 530-549, 2004.

MONTGOMERY, D. C. Introdução ao controle estatístico da qualidade. 4. ed. Rio de Janeiro: LTC Editora, 2004.

MUNRO, R. A. Linking Six Sigma with QS- 9000. Quality Progress, v. 33, n. 5, p. 47-53, 2000.

NICOLS, M. Quality tools in a service environment. ASQ Six Sigma Forum Magazine, v. 1, n. 6, 2006 .

PANDE, P. S.; NEUMAN, R. P.; CAVANAGH, R. $\mathrm{R}$. The six sigma way. how GE, Motorola, and other top companies are honing their performance. New York: McGraw-Hill, 2000.
PEREZ-WILSON, M. Six Sigma: understanding the concept, implications and challenges. Scottsdale: Advanced Systems Consultants, 1999.

PFEIFER, T; REISSIGER, W; CANALES, C. Integrating Six Sigma with quality management systems. The TQM Magazine, v. 16, n. 4, p. 241-249, 2004.

PINTO, S. B.; CARVALHO, M.M.; HO, L. L. Implementação de programas de qualidade: uma survey em empresas de grande porte no Brasil. Gestão \& Produção, v. 13, n. 2, p. 191203, 2006.

ROTONDARO, R. G. e vários colaboradores. Seis Sigma: estratégia gerencial para a melhoria de processos, produtos e serviços. São Paulo: Atlas, 2002.

SANTOS, A. B.; MARTINS, M. F. Modelo de referência para estruturar o seis sigma nas organizações. Gestão \& Produção, v. 15, n. 1 , p. 43-56, 2008

SEE, R. D. Improving the execution of Six Sigma methods and tools. ASQ Six Sigma Forum Magazine; n. 5, v. 4; ago. 2006.

VIEIRA FILHO, G. Gestão da qualidade total: uma abordagem prática. São Paulo: Alínea, 2003.

WERKEMA, M. C. C. Report Seis Sigma. São Paulo: Editora EPSE, 2002

WESSEL, G; BURCHER, P. Six Sigma for small and medium-sized enterprises. The TQM Magazine, v. 16, n. 4, p. 264-272, 2004.

YOUNG, A. Six Sigma: creating an advantage competitive. The Virtual Strategist, p. 38-41, 2001

\section{AGRADECIMENTOS}

Os autores do presente trabalho agradecem primeiramente às empresas que propiciaram a realização deste estudo. No entanto, a análise feita é de responsabilidade dos autores, não representando, portanto, a posição das empresas respondentes. Os autores agradecem também aos avaliadores pelas importantes recomendações e sugestões na revisão do texto, contribuindo significativamente para a melhoria na qualidade final do artigo. Finalmente, um agradecimento deve ser dirigido para o CNPq e CAPES pelo apoio ao projeto de pesquisa.

\section{SOBRE OS AUTORES}

\section{Eduardo Guilherme Satolo}

Universidade Metodista de Piracicaba (UNIMEP)

End.: Rodovia Iracemápolis - Santa Bárbara d’Oeste Km 01 - 13450-000 - Santa Bárbara d’Oeste

Tel.: (19) 3124-1767

E-mail: edgsatolo@unimep.br

\section{João Marcos Andrietta}

Elastotec S.A.

End.: Rua Pereira da Fonseca, nº 449 - Éden, 18103-043 - Sorocaba - SP

E-mail: j.m.andrietta@uol.com.br

\section{Paulo Augusto Cauchick Miguel}

Universidade Nove de Julho (UNINOVE)

End.: Av. Francisco Matarazzo, 612 - Prédio C - $1^{\circ}$ andar - Água Branca - São Paulo - SP

Tel.: (11) 3665-9325

E-mail: pacmiguel@uninove.br

\section{Felipe Araújo Calarge}

Universidade Nove de Julho (UNINOVE)

End.: Av. Francisco Matarazzo, 612 - Prédio C - $1^{\circ}$ andar - Água Branca - São Paulo - SP

Tel.: (11) 3665-9325

E-mail: fcalarge@uninove.br 
Satolo, E. G.; Andrietta, J. M.; Cauchick Miguel, P. A.; Calarge F. A. Análise da utilização de técnicas e ferramentas no programa Seis Sigma a partir de um levantamento tipo survey. Produção, v. 19, n. 2, p. 400-416, 2009

\section{APÊNDICE}

Relação das ferramentas e técnicas utilizadas nas etapas do método DMAIC nas empresas respondentes (\% dos respondentes da pesquisa).

\begin{tabular}{|c|c|c|c|c|c|c|c|}
\hline \multirow{2}{*}{ TÉCNICAS E FERRAMENTAS } & \multicolumn{7}{|c|}{ Etapa do método DMAIC } \\
\hline & Definir & Medir & Analisar & Melhorar & Controlar & Todas & Ranking \\
\hline Técnicas de Coleta de Dados & 55,13 & 89,74 & 46,15 & 34,62 & 34,62 & 52,05 & 1 \\
\hline Histograma & 33,33 & 74,36 & 67,95 & 28,21 & 37,18 & 48,21 & 2 \\
\hline Diagrama de Pareto & 57,69 & 64,10 & 64,10 & 25,64 & 26,92 & 47,69 & 3 \\
\hline Brainstorming & 65,38 & 38,46 & 61,54 & 44,87 & 17,95 & 45,64 & 4 \\
\hline Carta de Controle & 19,23 & 50,00 & 50,00 & 29,49 & 75,64 & 44,87 & 5 \\
\hline Índices de Capacidade & 26,92 & 57,69 & 47,44 & 39,74 & 48,72 & 44,10 & 6 \\
\hline Fluxograma & 60,26 & 51,28 & 46,15 & 34,62 & 20,51 & 42,56 & 7 \\
\hline Mapa de Processo & 55,13 & 46,15 & 50,00 & 34,62 & 16,67 & 40,51 & 8 \\
\hline Avaliação de Sistemas de Medição/Inspeção & 14,10 & 83,33 & 38,46 & 33,33 & 25,64 & 38,97 & 9 \\
\hline Controle Estatístico de Processo & 15,38 & 41,03 & 37,18 & 28,21 & 70,51 & 38,46 & 10 \\
\hline Mapeamento do Processo & 55,13 & 46,15 & 34,62 & 34,62 & 17,95 & 37,69 & 11 \\
\hline FMEA & 19,23 & 32,05 & 57,69 & 50,00 & 28,21 & 37,44 & 12 \\
\hline Mensuração de Defesa & 23,08 & 61,54 & 25,64 & 24,36 & 30,77 & 33,08 & 13 \\
\hline Mapa de Raciocínio & 37,18 & 35,90 & 30,77 & 30,77 & 25,64 & 32,05 & 14 \\
\hline Diagrama de Causa e Efeito & 25,64 & 38,46 & 70,51 & 23,08 & 2,56 & 32,05 & 15 \\
\hline Análise Econômica & 60,26 & 19,23 & 34,62 & 23,08 & 21,79 & 31,79 & 16 \\
\hline Técnicas de Amostragem & 12,82 & 66,67 & 32,05 & 19,23 & 25,64 & 31,28 & 17 \\
\hline Boxplot & 19,23 & 43,59 & 62,82 & 19,23 & 7,69 & 30,51 & 18 \\
\hline Análise do Tempo de Ciclo & 23,08 & 43,59 & 48,72 & 17,95 & 16,67 & 30,00 & 19 \\
\hline Análise de Variância & 8,97 & 28,21 & 75,64 & 23,08 & 8,97 & 28,97 & 20 \\
\hline Voz do Cliente & 65,38 & 23,08 & 19,23 & 15,38 & 20,51 & 28,72 & 21 \\
\hline Folha de Verificação & 12,82 & 48,72 & 26,92 & 17,95 & 37,18 & 28,72 & 22 \\
\hline Estratificação & 35,90 & 46,15 & 44,87 & 11,54 & 2,56 & 28,21 & 23 \\
\hline Análise de Causa Raiz & 25,64 & 24,36 & 74,36 & 8,97 & 3,85 & 27,44 & 24 \\
\hline Teste de Hipóteses & 0,00 & 14,10 & 71,79 & 33,33 & 11,54 & 26,15 & 25 \\
\hline Diagrama de Dispersão & 6,41 & 30,77 & 69,23 & 14,10 & 7,69 & 25,64 & 26 \\
\hline Planejamento de Experimentos & 2,56 & 8,97 & 50,00 & 56,41 & 6,41 & 24,87 & 27 \\
\hline Análise de Regressão & 6,41 & 16,67 & 79,49 & 15,38 & 3,85 & 24,36 & 28 \\
\hline $5 \mathrm{~W} 2 \mathrm{H}$ & 24,36 & 19,23 & 26,92 & 34,62 & 16,67 & 24,36 & 29 \\
\hline Gráfico Sequencial & 23,08 & 43,59 & 25,64 & 10,26 & 19,23 & 24,36 & 30 \\
\hline POKA-YOKE & 5,13 & 3,85 & 8,97 & 50,00 & 51,28 & 23,85 & 31 \\
\hline Procedimento Operacional Padrão & 7,69 & 8,97 & 12,82 & 42,31 & 44,87 & 23,33 & 32 \\
\hline Matriz de Priorização & 24,36 & 25,64 & 32,05 & 30,77 & 2,56 & 23,08 & 33 \\
\hline QFD & 37,18 & 24,36 & 26,92 & 15,38 & 5,13 & 21,79 & 34 \\
\hline Diagrama Árvore & 25,64 & 21,79 & 42,31 & 11,54 & 2,56 & 20,77 & 35 \\
\hline Project Charter & 61,54 & 7,69 & 7,69 & 10,26 & 14,10 & 20,26 & 36 \\
\hline SIPOC & 61,54 & 16,67 & 7,69 & 2,56 & 3,85 & 18,46 & 37 \\
\hline Análise de Tempo de Falhas & 8,97 & 25,64 & 43,59 & 7,69 & 5,13 & 18,21 & 38 \\
\hline Simulação & 1,28 & 8,97 & 26,92 & 47,44 & 6,41 & 18,21 & 39 \\
\hline Diagrama de Gantt & 25,64 & 16,67 & 17,95 & 20,51 & 8,97 & 17,95 & 40 \\
\hline Mapa de Produto & 25,64 & 23,08 & 19,23 & 15,38 & 5,13 & 17,69 & 41 \\
\hline Análise Multivariada & 5,13 & 12,82 & 51,28 & 10,26 & 1,28 & 16,15 & 42 \\
\hline Diagrama de Relações & 6,41 & 17,95 & 35,90 & 12,82 & 3,85 & 15,38 & 43 \\
\hline Diagrama de Afinidades & 12,82 & 15,38 & 33,33 & 8,97 & 2,56 & 14,62 & 44 \\
\hline Técnicas Estat. de Prev. Série Temporais & 7,69 & 12,82 & 26,92 & 11,54 & 14,10 & 14,62 & 45 \\
\hline Relatório de Anomalias & 10,26 & 14,10 & 12,82 & 16,67 & 19,23 & 14,62 & 46 \\
\hline Carta Multi-Van & 3,85 & 10,26 & 32,05 & 10,26 & 10,26 & 13,33 & 47 \\
\hline Diagrama de Matriz & 8,97 & 19,23 & 24,36 & 12,82 & 0,00 & 13,08 & 48 \\
\hline Stokeholder Analysis & 29,49 & 7,69 & 6,41 & 8,97 & 3,85 & 11,28 & 49 \\
\hline Teste de Vida Acelerada & 0,00 & 11,54 & 25,64 & 10,26 & 5,13 & 10,51 & 50 \\
\hline FTA & 2,56 & 6,41 & 30,77 & 7,69 & 3,85 & 10,26 & 51 \\
\hline Stokeholder & 29,49 & 6,41 & 1,28 & 6,41 & 3,85 & 9,49 & 52 \\
\hline Teste de Mercado & 5,13 & 11,54 & 14,10 & 11,54 & 5,13 & 9,49 & 53 \\
\hline PERT/COM & 8,97 & 8,97 & 3,85 & 14,10 & 2,56 & 7,69 & 54 \\
\hline Teste de Operação & 2,56 & 5,13 & 14,10 & 14,10 & 2,56 & 7,69 & 55 \\
\hline Operação Evolutiva & 2,56 & 5,13 & 11,54 & 15,38 & 2,56 & 7,44 & 56 \\
\hline PDPC & 3,85 & 7,69 & 6,41 & 10,26 & 1,28 & 5,90 & 57 \\
\hline OCAP & 0,00 & 3,85 & 5,13 & 5,13 & 12,82 & 5,38 & 58 \\
\hline
\end{tabular}

Legenda

Dez técnicas e ferramentas mais utilizadas nas etapas do método DMAIC.

Dez técnicas e ferramentas menos utilizadas nas etapas do método DMAIC. 